See Mun Lee, Kong Mun Lo and Edward R.T. Tiekink*

\title{
Crystal structure of (4-fluorobenzyl- $\mathrm{KC}$ )(bis(2-hydroxyethyl) carbamodithioato- $\left.\mathrm{k}^{2} S, S^{\prime}\right)\left(2,2^{\prime}\right.$-imino-diethanolato- $\left.\mathrm{K}^{3} \mathrm{~N}, 0, \mathrm{O}^{\prime}\right)$ tin(IV), $\mathrm{C}_{16} \mathrm{H}_{25} \mathrm{FN}_{2} \mathrm{O}_{4} \mathrm{~S}_{2} \mathrm{Sn}$
}

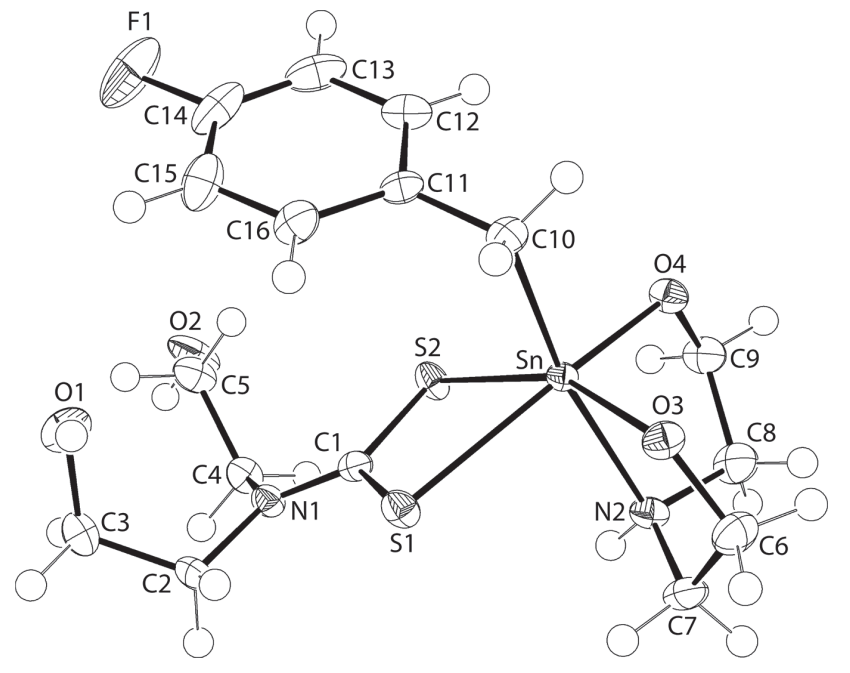

https://doi.org/10.1515/ncrs-2019-0711

Received September 20, 2019; accepted October 24, 2019; available online November 8, 2019

\section{Abstract}

$\mathrm{C}_{16} \mathrm{H}_{25} \mathrm{FN}_{2} \mathrm{O}_{4} \mathrm{~S}_{2} \mathrm{Sn}$, monoclinic, $P 2_{1} / n \quad$ (no. 14), $a=11.2227(1) \AA, \quad b=12.6793(1) \AA, \quad c=13.8731(1) \AA$, $\beta=98.282(1)^{\circ}, \quad V=1953.50(3) \AA^{3}, \quad Z=4, \quad R_{\mathrm{gt}}(F)=0.0198$, $w R_{\text {ref }}\left(F^{2}\right)=0.0507, T=100(2) \mathrm{K}$.

\section{CCDC no.: 1961138}

The molecular structure is shown in the figure. Table 1 contains crystallographic data and Table 2 contains the list of the atoms including atomic coordinates and displacement parameters.

\section{Source of material}

All chemicals and solvents were used as purchased without purification. The melting point was determined using a

Corresponding author: Edward R.T. Tiekink, Research Centre for Crystalline Materials, School of Science and Technology, Sunway University, 47500 Bandar Sunway, Selangor Darul Ehsan, Malaysia, e-mail: edwardt@sunway.edu.my. https://orcid.org/0000-00031401-1520

See Mun Lee and Kong Mun Lo: Research Centre for Crystalline Materials, School of Science and Technology, Sunway University, 47500 Bandar Sunway, Selangor Darul Ehsan, Malaysia
Table 1: Data collection and handling.

\begin{tabular}{|c|c|}
\hline Crystal: & Colourless block \\
\hline Size: & $0.15 \times 0.13 \times 0.09 \mathrm{~mm}$ \\
\hline Wavelength: & Cu $K \alpha$ radiation (1.54184 $\AA$ ) \\
\hline$\mu:$ & $12.7 \mathrm{~mm}^{-1}$ \\
\hline Diffractometer, scan mode: & XtaLAB Synergy, $\omega$ \\
\hline$\theta_{\max }$, completeness: & $67.1^{\circ},>99 \%$ \\
\hline$N(h k l)_{\text {measured }}, N(h k l)_{\text {unique }}, R_{\text {int }}:$ & $23919,3496,0.037$ \\
\hline Criterion for $I_{\mathrm{obs}}, N\left(h k l_{\mathrm{gt}}\right.$ : & $I_{\text {obs }}>2 \sigma\left(I_{\text {obs }}\right), 3360$ \\
\hline$N(\text { param })_{\text {refined }}:$ & 244 \\
\hline Programs: & $\begin{array}{l}\text { CrysAlis }{ }^{\text {PRO }}[1] \text {, SHELX }[2,3] \text {, } \\
\text { WinGX/ORTEP [4] }\end{array}$ \\
\hline
\end{tabular}

Table 2: Fractional atomic coordinates and isotropic or equivalent isotropic displacement parameters $\left(\AA^{2}\right)$.

\begin{tabular}{lrrrr}
\hline Atom & $\boldsymbol{x}$ & $\boldsymbol{y}$ & $\boldsymbol{z}$ & $\boldsymbol{U}_{\text {iso }}{ }^{*} \boldsymbol{U}_{\text {eq }}$ \\
\hline Sn & $0.33289(2)$ & $0.30356(2)$ & $0.40915(2)$ & $0.00921(6)$ \\
S1 & $0.45184(4)$ & $0.42766(4)$ & $0.30926(3)$ & $0.01390(11)$ \\
S2 & $0.43980(5)$ & $0.19570(4)$ & $0.28780(3)$ & $0.01364(11)$ \\
F1 & $0.89803(12)$ & $0.11300(13)$ & $0.48966(10)$ & $0.0395(4)$ \\
O1 & $0.82094(13)$ & $0.37685(12)$ & $0.25974(10)$ & $0.0211(3)$ \\
H10 & $0.814(3)$ & $0.4281(15)$ & $0.2963(16)$ & $0.032^{*}$ \\
O2 & $0.70132(15)$ & $0.05587(12)$ & $0.14059(10)$ & $0.0237(3)$ \\
H2O & $0.714(3)$ & $0.066(2)$ & $0.0834(9)$ & $0.036^{*}$ \\
O3 & $0.23599(12)$ & $0.42597(11)$ & $0.45757(9)$ & $0.0141(3)$ \\
O4 & $0.23611(13)$ & $0.17524(11)$ & $0.44008(9)$ & $0.0140(3)$ \\
N1 & $0.57226(16)$ & $0.31851(13)$ & $0.18900(12)$ & $0.0125(3)$ \\
N2 & $0.17021(16)$ & $0.31533(13)$ & $0.28969(12)$ & $0.0138(4)$ \\
H2N & $0.186(2)$ & $0.3042(17)$ & $0.2303(9)$ & $0.017^{*}$ \\
C1 & $0.49787(18)$ & $0.31489(15)$ & $0.25473(14)$ & $0.0120(4)$ \\
C2 & $0.62724(18)$ & $0.41761(16)$ & $0.16144(14)$ & $0.0155(4)$ \\
H2A & 0.608042 & 0.474740 & 0.205356 & $0.019^{*}$ \\
H2B & 0.591835 & 0.436800 & 0.094210 & $0.019^{*}$ \\
C3 & $0.76312(18)$ & $0.40906(17)$ & $0.16683(14)$ & $0.0169(4)$ \\
H3A & 0.781936 & 0.357754 & 0.117387 & $0.020^{*}$ \\
H3B & 0.795647 & 0.478432 & 0.150766 & $0.020^{*}$ \\
C4 & $0.59808(18)$ & $0.22320(17)$ & $0.13462(14)$ & $0.0143(4)$ \\
H4A & 0.622423 & 0.244796 & 0.071707 & $0.017^{*}$ \\
H4B & 0.523444 & 0.180959 & 0.120198 & $0.017^{*}$ \\
C5 & $0.69692(19)$ & $0.15421(17)$ & $0.18930(13)$ & $0.0180(4)$ \\
H5A & 0.775576 & 0.190412 & 0.192691 & $0.022^{*}$ \\
H5B & 0.680542 & 0.142172 & 0.256673 & $0.022^{*}$ \\
C6 & $0.12578(18)$ & $0.45534(18)$ & $0.40019(14)$ & $0.0190(4)$ \\
H6A & 0.114626 & 0.532545 & 0.404697 & $0.023^{*}$ \\
H6B & 0.058086 & 0.420405 & 0.426005 & $0.023^{*}$ \\
& & & &
\end{tabular}


Table 2 (continued)

\begin{tabular}{lrrrr}
\hline Atom & $\boldsymbol{x}$ & $\boldsymbol{y}$ & $\boldsymbol{z}$ & $\boldsymbol{U}_{\text {iso }}{ }^{*} \boldsymbol{U}_{\text {eq }}$ \\
\hline C7 & $0.12406(18)$ & $0.42442(16)$ & $0.29391(14)$ & $0.0172(4)$ \\
H7A & 0.040837 & 0.428557 & 0.258913 & $0.021^{*}$ \\
H7B & 0.175099 & 0.473432 & 0.262229 & $0.021^{*}$ \\
C8 & $0.08373(19)$ & $0.23244(18)$ & $0.31027(15)$ & $0.0200(4)$ \\
H8A & 0.035943 & 0.208386 & 0.248615 & $0.024^{*}$ \\
H8B & 0.027632 & 0.261438 & 0.352446 & $0.024^{*}$ \\
C9 & $0.15280(18)$ & $0.14039(17)$ & $0.36075(13)$ & $0.0178(4)$ \\
H9A & 0.095653 & 0.090324 & 0.384188 & $0.021^{*}$ \\
H9B & 0.196040 & 0.102765 & 0.313713 & $0.021^{*}$ \\
C10 & $0.45975(19)$ & $0.30397(15)$ & $0.54237(14)$ & $0.0146(4)$ \\
H10A & 0.474012 & 0.377766 & 0.564355 & $0.017^{*}$ \\
H10B & 0.423600 & 0.266020 & 0.593405 & $0.017^{*}$ \\
C11 & $0.57793(17)$ & $0.25412(17)$ & $0.53222(13)$ & $0.0135(4)$ \\
C12 & $0.59430(19)$ & $0.14486(17)$ & $0.54397(13)$ & $0.0182(4)$ \\
H12 & 0.530336 & 0.103075 & 0.561198 & $0.022^{*}$ \\
C13 & $0.7017(2)$ & $0.09657(18)$ & $0.53102(14)$ & $0.0235(5)$ \\
H13 & 0.712656 & 0.022774 & 0.540184 & $0.028^{*}$ \\
C14 & $0.79167(19)$ & $0.1590(2)$ & $0.50448(15)$ & $0.0250(5)$ \\
C15 & $0.78049(19)$ & $0.2663(2)$ & $0.49133(15)$ & $0.0240(5)$ \\
H15 & 0.844476 & 0.306889 & 0.472588 & $0.029^{*}$ \\
C16 & $0.6726(2)$ & $0.31362(17)$ & $0.50629(15)$ & $0.0181(4)$ \\
H16 & 0.663481 & 0.387772 & 0.498653 & $0.022^{*}$ \\
\hline
\end{tabular}

Mel-temp II digital melting point apparatus and was uncorrected. The IR spectrum was obtained on a Bruker Vertex 70v FTIR Spectrometer. The ${ }^{1} \mathrm{H}$ and ${ }^{13} \mathrm{C}\left\{{ }^{1} \mathrm{H}\right\}$ spectra were recorded at room temperature in DMSO- $\mathrm{d}_{6}$ solution on a Bruker Ascend $400 \mathrm{MHz}$ NMR spectrometer with chemical shifts relative to tetramethylsilane.

Di(4-fluorobenzyl)tin dichloride was synthesized by the direct reaction of 4-fluorobenzyl chloride (Merck) and metallic tin powder (Merck) in toluene according to a literature procedure [5]. The dithiocarbamate ligand was prepared in situ (methanol; $15 \mathrm{~mL}$ ) from the reaction of $\mathrm{CS}_{2}$ (Merck, $0.25 \mathrm{mmol}$ ) with diethanolamine (Merck, $0.25 \mathrm{mmol}$ ) and $\mathrm{NaOH}(0.02 \mathrm{~mL} ; 50 \% w / v) ; \mathrm{CS}_{2}$ was added dropwise into the methanol solution. The resulting solution was kept at $273 \mathrm{~K}$ for $1 \mathrm{~h}$. Next, di(4-fluorobenzyl)tin dichloride (Merck, $0.25 \mathrm{mmol}, 0.10 \mathrm{~g})$ in methanol $(10 \mathrm{~mL})$ was added into the solution and the resulting mixture was stirred for $3 \mathrm{~h}$. The filtrate was evaporated until an off-white precipitate was obtained. The precipitate was washed with $n$-hexane and recrystallised from a methanol-acetone solution. Crystals of the title compound were obtained from the slow evaporation of the solvent; the 2,2'-imino-diethanolate di-anion is derived from diethanolamine. Yield: $0.010 \mathrm{~g}$ (7.8\%). M.pt: 377-379 K. IR ( $\left.\mathrm{cm}^{-1}\right)$ : 3360(br) v(NH, OH), 1501(m) v(CN), 1064(s) v(CS), 1022(s) v(CS). ${ }^{1}$ H NMR (DMSO-d $\left.\mathrm{d}_{6}, \mathrm{ppm}\right): \delta 2.95$ (s, 2H, $\left.\mathrm{CH}_{2}\right), 3.42-3.50\left(\mathrm{~m}, 8 \mathrm{H}, \mathrm{NCH}_{2}\right), 3.65-3.73\left(\mathrm{~m}, 8 \mathrm{H}, \mathrm{OCH}_{2}\right)$, 4.88 (br, 3H, OH, NH), 6.91-7.30 (m, 4H, Ph-H). ${ }^{13} \mathbf{C}\left\{{ }^{1} \mathbf{H}\right\}$ NMR
(DMSO- $\left.\mathrm{d}_{6}, \mathrm{ppm}\right): \delta 50.0\left(\mathrm{CH}_{2}\right), 58.4\left(\mathrm{NCH}_{2}\right), 59.0\left(\mathrm{NCH}_{2}\right), 62.1$ $\left(\mathrm{OCH}_{2}\right), 66.9\left(\mathrm{OCH}_{2}\right), 114.5,128.5,130.1,138.5(\mathrm{Ph}-\mathrm{C}), 187.5(\mathrm{CS})$.

\section{Experimental details}

The C-bound $\mathrm{H}$ atoms were geometrically placed $(\mathrm{C}-\mathrm{H}=0.95-0.99 \AA)$ and refined as riding with $U_{\text {iso }}(\mathrm{H})=1.2 U_{\text {eq }}(\mathrm{C})$. The $\mathrm{O}$ - and $\mathrm{N}$-bound $\mathrm{H}$-atoms were located in a difference Fourier map but, were refined with distance restraints of $\mathrm{O}-\mathrm{H}=0.84 \pm 0.01 \AA$ and $\mathrm{N}-$ $\mathrm{H}=0.88 \pm 0.01 \AA$, respectively, and with $U_{\text {iso }}(\mathrm{H})$ set to $1.5 U_{\text {eq }}(0)$ and $1.2 U_{\text {eq }}(\mathrm{N})$, respectively.

\section{Comment}

The 1,1-dithiolate, e.g. dithiocarbamate $\left({ }^{-} \mathrm{S}_{2} \mathrm{CNR}_{2}\right)$, compounds of the zinc-triad elements [5], main group elements [6, 7], including tin [8], are well-known to form secondary $\mathrm{M} \cdots \mathrm{S}$ bonding interactions in their crystal structures $[9,10]$. However, when concurrently bound to potentially bidentate, bridging bi-pyridyl ligands, with the aim of increasing the dimensionality of the supramolecular association, the secondary bonding is generally lost, as amply demonstrated in the structural chemistry of the zinc-triad 1,1-dithiolates [11]. One way of overcoming this limitation is to introduce hydrogen bonding functionality in the $\mathrm{R}$ groups, e.g. hydroxyethyl groups, as the resultant hydrogen bonding can lead to one-, two- and, sometimes, three-dimensional aggregation in the solid-state [5-8, 11]. In the title mixed ligand, organotin compound, (4$\left.\mathrm{FC}_{6} \mathrm{H}_{4} \mathrm{CH}_{2}\right) \mathrm{Sn}\left[\mathrm{OCH}_{2} \mathrm{CH}_{2} \mathrm{~N}(\mathrm{H}) \mathrm{CH}_{2} \mathrm{CH}_{2} \mathrm{O}\right]\left[\mathrm{S}_{2} \mathrm{CN}\left(\mathrm{CH}_{2} \mathrm{CH}_{2} \mathrm{OH}\right)_{2}\right]$, (I), the dithiocarbamate ligand bears two hydroxyethyl groups, each capable of hydrogen bonding. Herein, the crystal and molecular structures of (I) are described along with an analysis of the calculated Hirshfeld surfaces.

The molecular structure of (I) is shown in the figure (70\% displacement ellipsoids). The tin atom is coordinated by the methylene-carbon atom of the 4-fluorobenzyl substituent, two sulphur atoms of the dithiocarbamate ligand along with the imino-nitrogen and two ethoxide-oxygen atoms of the di-anionic, tridentate 2,2'-imino-diethanolate ligand. The dithiocarbamate ligand chelates in a symmetric mode as seen in the equivalence of the $\mathrm{Sn}-\mathrm{S} 1$ [2.5906(5) $\AA$ ] and Sn-S2 [2.5934(5) $\AA$ ] bond lengths; this equivalence is reflected in the equality of the associated $\mathrm{C}-\mathrm{S}$ bonds [ $\mathrm{C1}-$ $\mathrm{S} 1, \mathrm{~S} 2=1.731(2)$ and 1.734(2) $\AA$ ]. There is a small dispar-

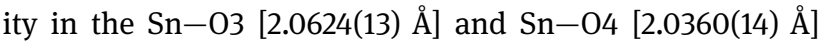
bond lengths despite each oxygen atom being approximately trans to a thiolate-sulphur atom; the Sn-N2 bond length $=2.2870(17) \AA$. The resultant $\mathrm{CNO}_{2} \mathrm{~S}_{2}$ donor set defines an approximate octahedron with the major distortion related to the acute S1-Sn-S2 chelate angle of $69.564(15)^{\circ}$. The N1$\mathrm{Sn}-\mathrm{C} 10\left[167.65(7)^{\circ}\right]$ and, in particular, S1-Sn-04 [158.40(4) $\left.{ }^{\circ}\right]$ 
and $\mathrm{S} 2-\mathrm{Sn}-\mathrm{O} 3\left[157.41(4)^{\circ}\right]$ trans angles deviate from the ideal $180^{\circ}$. To a first approximation, the $\mathrm{O}_{2} \mathrm{~S}_{2}$ atoms define a square-plane [r.m.s. deviation $=0.0348 \AA$ ] and the $\mathrm{Sn}$ atom lies $0.2859(6)$ above this plane in the direction of the 4fluorobenzyl-C10 atom. The tridentate mode of coordination for the 2,2'-imino-diethanolate ligand gives rise to two five-membered $\mathrm{Sn}, \mathrm{O}, \mathrm{N}, \mathrm{C}_{2}$ rings, which adopt distinct conformations. Thus, the 03-chelate is twisted about the C7-N2 bond. By contrast, the 04-ring has an envelope conformation with the flap atom, C9, lying 0.555(3) A out of the leastsquares plane through the remaining four atoms [r.m.s. deviation $=0.044 \AA$ ].

Tin(II), tin(IV) and organotin(IV) dithiocarbamate compounds are well known in the literature with coordination modes ranging from symmetric as in (I) to effectively monodentate in triorganotin derivatives but often adopt asymmetric modes of coordination [8]. By contrast, there is only one literature precedent for a tin compound with the 2,2'-imino-diethanolate ligand, namely in the structure of $\mathrm{Sn}\left(\mathrm{OCH}_{2} \mathrm{CH}_{2} \mathrm{~N}(\mathrm{H}) \mathrm{CH}_{2} \mathrm{CH}_{2} \mathrm{O}\right)\left(\mathrm{CH}_{2} \mathrm{Si}(\mathrm{Me})_{2} \mathrm{OSi}(\mathrm{Me})_{2} \mathrm{CH}_{2}\right)$ [12].

The crystal of (I) features conventional $\mathrm{O}-\mathrm{H} \cdots \mathrm{O}$ hydrogen bonding leading to a supramolecular layer parallel to

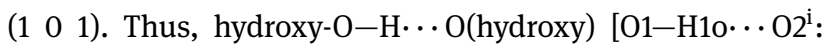
$\mathrm{H} 1 \mathrm{o} \cdots \mathrm{O} 2^{\mathrm{i}}=1.86(2) \AA$, $01 \cdots \mathrm{O} 2^{\mathrm{i}}=2.688(2) \AA$ with angle at $\mathrm{H} 1 \mathrm{o}=171(2)^{\circ}$ for symmetry operation (i) $3 / 2-x, 1 / 2+y$, $1 / 2-z]$ and hydroxy-O $-\mathrm{H} \cdots \mathrm{O}$ (ethanolate) $\left[02-\mathrm{H} 2 \mathrm{o} \cdots \mathrm{O} 3^{\mathrm{ii}}\right.$ : $\mathrm{H} 2 \mathrm{O} \cdots \mathrm{O} 3^{\mathrm{ii}}=1.801(15) \AA, 02 \cdots \mathrm{O} 3^{\mathrm{ii}}=2.6336(19) \AA$ with angle at $\mathrm{H} 2 \mathrm{o}=174(3)^{\circ}$ for (ii) $\left.1 / 2+x, 1 / 2-y,-1 / 2+z\right]$ hydrogen bonds feature in the molecular packing. The formation of the latter hydrogen bonding interaction provides a rationale for the elongation of the $\mathrm{Sn}-\mathrm{O} 3$ bond length with respect to the $\mathrm{Sn}-\mathrm{O} 4$ bond. The connections between layers to consolidate the three-dimensional molecular packing are imino- $\mathrm{N}-\mathrm{H} \cdots \pi$ (phenyl) interactions $[\mathrm{N} 2-\mathrm{H} 2 \mathrm{n} \cdots \mathrm{Cg}(\mathrm{C} 11-$ C16 $)^{\mathrm{iii}}: \quad \mathrm{H} 2 \mathrm{n} \cdots \mathrm{Cg}(\mathrm{C} 11-\mathrm{C} 16)^{\mathrm{iii}}=2.946(13) \AA$ A, $\quad \mathrm{N} 2 \cdots \mathrm{Cg}(\mathrm{C} 11-$ $\mathrm{C} 16)^{\mathrm{iii}}=3.8061(18) \AA$ with angle at $\mathrm{H} 2 \mathrm{n}=166.7(18)^{\circ}$ for (iii) $-1 / 2+x, 1 / 2-y,-1 / 2+z]$.

In order to analyse the molecular packing further, in particular the influence of other non-covalent interactions operating in the crystal of (I), an analysis of the calculated Hirshfeld surfaces/two-dimensional fingerprint plots (overall and individual surface contacts) was conducted employing Crystal Explorer 17 [13] and literature procedures [14]. Reflecting the significant $\mathrm{O}-\mathrm{H} \cdots \mathrm{O}$ hydrogen bonding interactions along with some $\mathrm{C}-\mathrm{H} \cdots \mathrm{O}$ contacts shorter than the sum of the respective van der Waals radii in the crystal, $\mathrm{O} \cdots \mathrm{H} / \mathrm{H} \cdots \mathrm{O}$ contacts, at $17.8 \%$, are a major contributor to surface contacts, as are $\mathrm{C} \cdots \mathrm{H} / \mathrm{H} \cdots \mathrm{C}$ contacts $[7.0 \%]$ but, neither match the dominance of $\mathrm{H} \cdot \cdots \mathrm{H}$ contacts, i.e. $57.5 \%$.
The other major contributions come from $\mathrm{F} \cdots \mathrm{H} / \mathrm{H} \cdots \mathrm{F}[9.2 \%]$ and $\mathrm{S} \cdots \mathrm{H} / \mathrm{H} \cdots \mathrm{S}[\mathrm{7.1} \%]$, with some $\mathrm{F} \cdot \mathrm{H}$ contacts within distances less than the sum of their van der Waals radii.

Acknowledgements: Sunway University Sdn Bhd is thanked for financial support of this work through Grant No. STRRCTR-RCCM-001-2019.

\section{References}

1. Agilent Technologies: CrysAlis ${ }^{\mathrm{PRO}}$. Agilent Technologies, Santa Clara, CA, USA (2010).

2. Sheldrick, G. M.: A short history of SHELX. Acta Crystallogr. A64 (2008) 112-122.

3. Sheldrick, G. M.: Crystal structure refinement with SHELXL. Acta Crystallogr. C71 (2015) 3-8.

4. Farrugia, L. J.: WinGX and ORTEP for Windows: an update. J. Appl. Crystallogr. 45 (2012) 849-854.

5. Tiekink, E. R. T.: Exploring the topological landscape exhibited by binary zinc-triad 1,1-dithiolates. Crystals 8 (2018) article no. 292 (34 pages).

6. Tiekink, E. R. T.: Aggregation patterns in the crystal structures of organometallic Group XV 1,1-dithiolates: the influence of the Lewis acidity of the central atom, metal- and ligand-bound steric bulk, and coordination potential of the 1,1-dithiolate ligands upon supramolecular architecture. CrystEngComm 8 (2006) 104-118.

7. Lai, C. S.; Tiekink, E. R. T.: Prevalence of intermolecular $\mathrm{Bi}$...S interactions in bismuth dithiocarbamate compounds: $\mathrm{Bi}\left(\mathrm{S}_{2} \mathrm{CNR}_{2}\right)_{3}$. Z. Kristallogr. 222 (2007) 532-538.

8. Tiekink, E. R. T.: Tin dithiocarbamates: applications and structures. Appl. Organomet. Chem. 22 (2008) 533-550.

9. Alcock, N. W.: Secondary bonding to nonmetallic elements. Adv. Inorg. Chem. Radiochem. 15 (1972) 1-58.

10. Tiekink, E. R. T.: Supramolecular assembly based on "emerging" intermolecular interactions of particular interest to coordination chemists. Coord. Chem. Rev. 345 (2017) 209-228.

11. Tiekink, E. R. T.: Perplexing coordination behaviour of potentially bridging bipyridyl-type ligands in the coordination chemistry of zinc and cadmium 1,1-dithiolate compounds. Crystals 8 (2018) article no. 18 (29 pages).

12. Gurkova, S. N.; Tandura, S. N.; Gusev, A. I.; Alekseev, N. V.; Chernyshev, A. E.; Stepina, E. M.; Kovaleva, E. A.; Grachev, A. A.; Shiryaev, V. I.: Synthesis and structure of a spirostannocane: 2,2,4,4-tetramethyl-2,4-disila-6-stanna-3, 7,13-trioxa-10-aza-spiro[5.7]tridecane. Metalloorg. Khim. (in Russ.) 1 (1988) 839-845.

13. Turner, M. J.; McKinnon, J. J.; Wolff, S. K.; Grimwood, D. J.; Spackman, P. R.; Jayatilaka, D.; Spackman, M. A.: Crystal Explorer v17. The University of Western Australia, Australia (2017).

14. Tan, S. L.; Jotani, M. M.; Tiekink, E. R. T.: Utilizing Hirshfeld surface calculations, non-covalent interaction $(\mathrm{NCl})$ plots and the calculation of interaction energies in the analysis of molecular packing. Acta Crystallogr. E75 (2019) 308-318. 